\title{
Cholestasis of pregnancy: effects on maternal and fetal outcome
}

\author{
Nazia Hassan"1, Rabia Khurshid ${ }^{2}$, Mudasir Muzamil ${ }^{3 *}$, Shameema Parveen ${ }^{2}$
}

\begin{abstract}
${ }^{1}$ Department of Obstetrics and Gynecology, SKIMS, Medical College and Hospital, Srinagar, Jammu and Kashmir, India

${ }^{2}$ Department of Obstetrics and Gynecology, ${ }^{3}$ Department of Cardiology, SKIMS, Soura Srinagar, Jammu and Kashmir, India
\end{abstract}

Received: 13 July 2020

Accepted: 20 July 2020

\section{*Correspondence:}

Dr. Mudasir Muzamil,

E-mail: drmmuzamil@gmail.com

Copyright: (c) the author(s), publisher and licensee Medip Academy. This is an open-access article distributed under the terms of the Creative Commons Attribution Non-Commercial License, which permits unrestricted non-commercial use, distribution, and reproduction in any medium, provided the original work is properly cited.

\section{ABSTRACT}

Background: Intrahepatic cholestasis of pregnancy (ICP) typically occurs in late pregnancy affecting $1.5-2 \%$ pregnancies. Limited data is available regarding its fetal and maternal implications. This study aims to assess the impact of ICP on maternal and fetal outcome.

Methods: A total 200 patients with pruritus in later half of pregnancy were studied over a period of 18 months out of which 135 were diagnosed as ICP. Clinical and biochemical parameters like serum aspartate aminotransferase, alanine aminotransferase, alkaline phosphatase, total protein, and gamma glutamyl transferase was recorded. Maternal and fetal outcome was noted in the form of LSCS rate, preterm births, fetal distress and neonatal ICU admissions.

Results: In this study, most common symptom was pruritus. Most of cases had onset of symptoms between 32-36 weeks. High LSCS rates were seen among cases. Intrapartum complications viz. meconium staining of amniotic fluid $(57.8 \%)$, preterm delivery $(11.9 \%)$, fetal distress $(42.2 \%)$ were significantly higher in study population and there was high incidence of NICU admissions (49. 6\% neonates) among cases mostly due to meconium aspiration and prematurity.

Conclusions: ICP increases maternal morbidity and is associated with adverse perinatal outcome viz. increased risk of fetal distress, preterm births and sudden IUD at term as evidenced in this study. A timely intervention at 37-38 weeks will reduce the adverse outcomes.

Keywords: Fetal distress, Intrahepatic cholestasis of pregnancy, Labour, Preterm, Pregnancy

\section{INTRODUCTION}

Intrahepatic cholestasis of pregnancy (ICP), also called obstetric cholestasis, is a liver condition of pregnancy, characterized by pruritus and the biochemical finding of elevated serum bile acids, often in the presence of other signs of liver dysfunction. By definition, ICP is confined to pregnancy and the peripartum period and is diagnosed following exclusion of other etiologies for cholestasis. In addition to the maternal symptomatology, ICP can be associated with adverse fetal outcomes, such as spontaneous preterm birth, meconium staining of the amniotic fluid, and stillbirth; hence, appropriate recognition and management are significiant. ${ }^{1}$ ICP typically occurs in late pregnancy affecting $1.5-2 \%$ pregnancies. Pruritus in second half of pregnancy which is otherwise unexplained is the most characteristic clinical manifestation. The pruritus is more severe at night and in palms and soles. ${ }^{2}$

Most patients with ICP do not develop clinical jaundice. The liver function predominantly shows features of cholestasis. The most characteristic laboratory abnormality is high serum bile acid levels ( $\geq 10 \mu \mathrm{mol} / \mathrm{L})$ which may be elevated up to 100 - fold. Severe obstetric cholestasis is defined by levels $>40 \mu \mathrm{mol} / \mathrm{L}$. Other findings are conjugated hyperbilirubinemia, increase in serum ALP, gamma glutamyl transferase (GGT) and 
serum aminotransferases are normal or only minimally elevated. The synthetic function of the liver and the liver architecture remains unaltered. ICP progresses until the time of delivery. Pruritus disappears within 24-48 hours postpartum, but biochemical and histological abnormalities may take weeks to months to resolve. ICP may recur in subsequent pregnancies in $60-70 \%$, although not necessarily as severe as the first episode. ${ }^{3}$

The fetal complications are significantly increased, when the serum bile acid levels are greater than $40 \mu \mathrm{mol} / \mathrm{L} .{ }^{4}$ Based on a few studies, it has been hypothesized that elevated bile acid levels can lead to surfactant depletion in the alveoli resulting in respiratory distress. ${ }^{5}$ Prevalence in women of Indian origin is 5\%.6 Prevalence may have seasonal cycles and may be more prevalent in the winters. $^{7}$

Risk factors for ICP include ethnicity, family history of biliary disease, hepatitis $\mathrm{C}$, multi-fetal gestation, maternal age greater than 35 years. ${ }^{8}$ Etiology of ICP is multifactorial: Genetic, hormonal and environmental factors have important roles. ${ }^{9}$

\section{Genetic factors}

- Positive family history (35\% of patients)

- Recurrence of ICP in $45-70 \%$ of subsequent pregnancy is seen 10

- Several potential genes associated with IHCP are ABCB4MDR-3 (multidrug resistance, pglycoprotein), ATP 8 B1 and ABCB 11 (phospholipid transporter). ${ }^{11}$

\section{Hormonal factors}

- Increased circulating estrogens and progestogens may play a role 12

- Twin and triplet pregnancies associated with higher hormone levels show higher incidence of ICP13

- Estrogens interfere with clearance of bile from liver and progesterone interfere with clearance of estrogens from liver

\section{Nutritional factors}

- Selenium deficiency leads to defective bile formation or secretion because of its role as a cofactor for several oxidative hepatic enzymes. ${ }^{14}$

\section{Environmental factors}

- ICP may have seasonal cycles and may be more prevalent in winters. ${ }^{7}$

There is increased incidence of preterm delivery, low birth weight babies, meconium staining of liquor, fetal bradycardia, fetal distress and IUD.

\section{Diagnosis of ICP}

\section{It is a diagnosis of exclusion}

- Typical history of pruritus without rash

- Abnormal liver function tests

- Exclusion of other causes of itching and abnormal liver function tests.

\section{Management of ICP}

It involves relief of pruritus and reducing the perinatal risks and ensure safe delivery.

- Local application of calamine lotion or aqueous cream with menthol

- Ursodeoxycholic acid (UDCA) is so far the most effective treatment to reduce the symptom of pruritus and improve liver function. Whether it offers any protection to the fetus or prevent stillbirth is not clear

- Oral Vitamin $\mathrm{K}$ in the dose of 5-10 mg orally daily should be given, particularly those with prolonged prothrombin time, which helps to reduce the risk of postpartum hemorrhage and fetal or neonatal bleeding $^{2}$

- Planned early delivery at 37-38 weeks is safer than spontaneous onset of labour to avoid the risk of stillbirth.

\section{Aims and objectives}

- To determine maternal and peri-natal outcome in patients with cholestasis of pregnancy.

- Study of liver function tests in obstetric cholestasis:

- ALT (Alanine transaminase)

- AST (Aspartate transaminase)

- GGT (Gamma-glutamyl transferase)

- ALP (Alkaline phosphatase)

\section{METHODS}

The present study is a prospective study which was conducted in the postgraduate department of obstetrics and gynecology, Sher-i-Kashmir Institute of Medical Sciences (SKIMS) Soura Srinagar. The study was conducted over a period of 18 months from August 2017 to January 2019. 200 patients with pruritus in later half of pregnancy were studied, out of which 135 were diagnosed as ICP and rest 65 were set as controls (did not conform to diagnosis of ICP as defined-viral hepatitis, pruritis with rash, atopy, drugs, obstructive jaundicecholedocholithiasis).

\section{Inclusion criteria}

- $\quad$ Patients with ICP

- Gestational age more than 28 weeks (calculated from last menstrual period and confirmed on ultrasound).

- Abnormal liver function tests. 


\section{Exclusion criteria}

- Patients with ICP

- Gestational age more than 28 weeks (calculated from last menstrual period and confirmed on ultrasound).

- Abnormal liver function tests.

Patient specific information was collected about

- Pruritus in previous pregnancy

- OCP intake

- History of gall stones

- Family history of ICP

- History of unexplained IUD at term

- Gestational age at the onset of pruritus.

Women were followed up regularly up to one week after delivery. Maternal and fetal outcomes were noted in terms of: gestational age at delivery and onset of labour, mode of onset of labour and delivery (vaginal or LSCS), complications viz.: abruptio placenta, postpartum haemorrhage, DIC, preterm or term birth, IUD, still birth, fetal weight and Apgar score at birth and $5 \mathrm{~min}$, fetal distress and NICU admissions.

\section{Ethical aspects}

A written informed consent was obtained from all the study subjects. The protocol was first submitted for clearance from departmental committee that looks into the technical and academic aspects of Biomedical Research in the Department of Obstetrics and Gynecology SKIMS. After getting departmental committee approval, the protocol was submitted to the "institutional ethical committee" (IEC-SKIMS) for formal approval. Being an observational study, the only ethical issue involved in the study was taking an extra blood sample for other non-routine tests if needed.

\section{Statistical analysis}

The recorded data was compiled and then exported to data editor of SPSS version 20.0 (SPSS Inc., Chicago, Illinois, USA). Continuous variables were expressed as Mean \pm SD and categorical variables were summarized as frequencies and percentages. Student's independent t-test was employed for comparing continuous variables. Chi- square test or Fisher's exact test, whichever appropriate, was applied for comparing categorical variables. A pvalue of less than 0.05 was considered statistically significant. All p-values were two tailed.

\section{RESULTS}

A total 200 patients with pruritus in later half of pregnancy were studied, out of which 135 were diagnosed as ICP. The mean age at time of delivery was $28.4 \pm 3.63$ years in cases and $28.9 \pm 3.62$ years in controls. Most of the ICP population, $56.3 \%$ was nulliparous.

Table 1: Gestational age at the onset of symptoms in cases.

\begin{tabular}{|ll|l|}
\hline Gestational age (weeks) & Frequency & Percentage \\
\hline$<28$ & 6 & $4.4 \%$ \\
\hline $28-32$ & 25 & $18.5 \%$ \\
\hline $32-36$ & 96 & $71.1 \%$ \\
\hline$\geq 36$ & 8 & $5.9 \%$ \\
\hline Total & 135 & $100 \%$ \\
\hline
\end{tabular}

Most of cases had onset of symptoms between 32-36 weeks (Table 1). Majority (83\%) of patients were term at delivery (Table 2) and the onset of labour was induced in $52.6 \%$, spontaneous in $25.9 \%$ and elective LSCS was done in $21.5 \%$.

Significantly higher LSCS (75.6\%) rates were seen among cases, vaginal delivery and vacuum assisted delivery were seen in $23 \%$ and $1.5 \%$ respectively. Among controls LSCS was done in $50.8 \%$ (Table 3).

In spontaneous onset of labour group, LSCS predominated among ICP group in $54.3 \%$ versus $29 \%$ $(\mathrm{p}=0.038)$ and vaginal delivery dominated as mode of delivery among controls i.e., in $71 \%$ vs. $45.7 \%$ in ICP group $(\mathrm{p}=0.038)$. In induction of labour group LSCS predominated as the mode of delivery among cases $80.3 \%$ versus $58.35 \quad(\mathrm{p}=0.037)$ followed by vaginal delivery in $16.9 \%$ of cases (Table 4).

Table 3 shows a significantly higher rate of LSCS in ICP group $(75.6 \%$ versus $50.8 \%$ ). It is also seen that the vaginal deliveries were significantly higher in non ICP group ( $49.2 \%$ versus $23 \%)$.

Table 2: Distribution of study patients as per gestational age at delivery.

\begin{tabular}{|c|c|c|c|c|c|}
\hline \multirow{2}{*}{$\begin{array}{l}\text { Gestational age at } \\
\text { delivery }\end{array}$} & \multicolumn{2}{|c|}{ Cases } & \multicolumn{2}{|c|}{ Controls } & \multirow[b]{2}{*}{ p-value } \\
\hline & No. & $\%$ & No. & $\%$ & \\
\hline Preterm & 17 & $12.6 \%$ & 4 & $6.2 \%$ & \multirow{4}{*}{0.269} \\
\hline Term & 112 & $83.0 \%$ & 56 & $86.2 \%$ & \\
\hline Post-term & 6 & $4.4 \%$ & 5 & $7.7 \%$ & \\
\hline Total & 135 & $100 \%$ & 65 & $100 \%$ & \\
\hline
\end{tabular}


Table 3: Distribution of study patients as per mode of delivery.

\begin{tabular}{|c|c|c|c|c|c|}
\hline \multirow{2}{*}{ Mode of delivery } & \multicolumn{2}{|c|}{ Cases } & \multicolumn{2}{|c|}{ Controls } & \multirow{2}{*}{ p-value } \\
\hline & No. & $\%$ & No. & $\%$ & \\
\hline LSCS & 102 & $75.6 \%$ & 33 & $50.8 \%$ & \multirow{4}{*}{$0.001 *$} \\
\hline Vaginal & 31 & $23.0 \%$ & 32 & $49.2 \%$ & \\
\hline Ventouse & 2 & $1.5 \%$ & 0 & $0.0 \%$ & \\
\hline Total & 135 & $100 \%$ & 65 & $100 \%$ & \\
\hline
\end{tabular}

*Statistically significant difference (p-value $<0.05)$.

Table 4: Delivery outcome in cases and controls as per onset of labour.

\begin{tabular}{|c|c|c|c|c|c|c|}
\hline \multirow{2}{*}{\multicolumn{2}{|c|}{ Onset of labour }} & \multicolumn{2}{|c|}{ Cases } & \multicolumn{2}{|c|}{ Controls } & \multirow{2}{*}{ p-value } \\
\hline & & No. & $\%$ & No. & $\%$ & \\
\hline \multirow{3}{*}{ Spontaneous labour } & LSCS & 19 & $54.3 \%$ & 9 & $29.0 \%$ & \multirow{3}{*}{$0.038 *$} \\
\hline & Vaginal & 16 & $45.7 \%$ & 22 & $71.0 \%$ & \\
\hline & Ventouse & 0 & $0.0 \%$ & 0 & $0.0 \%$ & \\
\hline \multirow{3}{*}{ Induced labour } & LSCS & 57 & $80.3 \%$ & 14 & $58.3 \%$ & \multirow{3}{*}{$0.037 *$} \\
\hline & Vaginal & 12 & $16.9 \%$ & 10 & $41.7 \%$ & \\
\hline & Ventouse & 2 & $2.8 \%$ & 0 & $0.0 \%$ & \\
\hline
\end{tabular}

*Statistically significant difference (p-value $<0.05)$.

Table 5: Intrapartum complications in cases and controls.

\begin{tabular}{|c|c|c|c|c|c|}
\hline \multirow{2}{*}{$\begin{array}{l}\text { Intrapartum } \\
\text { complications }\end{array}$} & \multicolumn{2}{|c|}{ Cases } & \multicolumn{2}{|c|}{ Controls } & \multirow{2}{*}{ p-value } \\
\hline & No. & $\%$ & No. & $\%$ & \\
\hline Meconium & 78 & $57.8 \%$ & 17 & $26.2 \%$ & $<0.001 *$ \\
\hline Preterm delivery & 16 & $11.9 \%$ & 4 & $6.2 \%$ & 0.208 \\
\hline Abruption & 0 & $0.0 \%$ & 0 & $0.0 \%$ & - \\
\hline Adherent placenta & 6 & $4.4 \%$ & 0 & $0.0 \%$ & 0.181 \\
\hline Fetal distress & 57 & $42.2 \%$ & 16 & $24.6 \%$ & $0.015 *$ \\
\hline
\end{tabular}

*Statistically significant difference (p-value $<0.05)$.

Table 6: Perinatal outcome in cases and controls.

\begin{tabular}{|c|c|c|c|c|c|}
\hline \multirow{2}{*}{$\begin{array}{l}\text { Intrapartum } \\
\text { complications }\end{array}$} & \multicolumn{2}{|l|}{ Cases } & \multicolumn{2}{|c|}{ Controls } & \multirow{2}{*}{ p-value } \\
\hline & No. & $\%$ & No. & $\%$ & \\
\hline IUD & 3 & $2.2 \%$ & 0 & $0.0 \%$ & 0.552 \\
\hline Meconium & 71 & $52.6 \%$ & 15 & $23.1 \%$ & $<0.001 *$ \\
\hline Still birth & 3 & $2.2 \%$ & 0 & $0.0 \%$ & 0.552 \\
\hline Birth weight (kg) & $3.03 \pm 0.407$ & & 3.01 & & 0.807 \\
\hline Fetal distress & 82 & $60.7 \%$ & 16 & $24.6 \%$ & $<0.001 *$ \\
\hline Still birth & 3 & $2.2 \%$ & 0 & $0.0 \%$ & 0.552 \\
\hline \multicolumn{6}{|l|}{ Apgar score } \\
\hline At birth & $6.92 \pm 0.9$ & & 7.13 & & 0.154 \\
\hline At $5 \mathrm{~min}$ & $8.13 \pm 1.34$ & & 8.41 & & 0.123 \\
\hline NICU admission & 67 & $49.6 \%$ & 10 & $15.4 \%$ & $<0.001 *$ \\
\hline
\end{tabular}

*Statistically significant difference (p-value $<0.05$ ).

The Table 4 provides important information regarding the mode of delivery when considered in relation to the mode of onset of labour. While as mentioned there was a higher tendency for LSCS rates in ICP group in general, the LSCS rates were significantly higher when labour was induced. This could be due to increased fetal distress in this, at risk pregnant population as result of induction.
There were no significant differences in occurrence of PPH and hematoma in cases $(15.6 \%, 3.0 \%)$ and controls $(9.2 \%, 3.1 \%)$ although PPH prevalence was numerically higher in ICP group (Table 5). Table 5 shows the increased risk of meconium and fetal distress in ICP group. Preterm births though numerically higher in ICP 
group, did not show any statistically significant difference between the two groups.

In addition to significantly high incidence of $(49.6 \%$ versus $15.4 \%$ ) NICU admissions, meconium staining of liquor and fetal distress showed statistically significant higher prevalence in cases as compared to controls (Table 6). Results also showed significant abnormal GGT levels in cases $(34.8 \%)$ versus controls $(34.8 \%)$ and increased serum Bilirubin in $27.4 \%$ cases as against $1.5 \%$ in controls. Table 6 shows the poor fetal outcome in ICP group with significantly higher rates of meconium, fetal distress and NICU admissions. There were also 3 still births and 3 IUDs in ICP group and none among controls but it was not statistically significant (could be due to smaller control group to establish the significance).

\section{DISCUSSION}

ICP is a pregnancy specific liver disorder seen in the later half of the pregnancy and is associated with increased rates of adverse fetal outcomes. Though, maternal effects of ICP are benign; however, there is a clear association between ICP and higher frequency of fetal distress, preterm delivery, and sudden intrauterine death. Most common symptom was pruritus and most of the patients developed pruritus between 32-36 weeks of gestation.

There was no significant difference in occurrence of term delivery ( $83 \%$ versus $86.1 \%$ ) or preterm delivery $(12.0 \%$ versus $6.2 \%$ ) though preterm deliveries were numerically higher in ICP group. These findings were consistent with the study by Alsulyman OM et al (14\% versus $7.6 \%)$ which could be related to timely intervention, institution of bile acid sequestrants and timely termination of pregnancy. ${ }^{15}$

However, a significant difference in the mode of onset of labour was observed. Only $25.9 \%$ cases had spontaneous onset of labour against $47.7 \%$ controls. In $52.6 \%$ cases labour was induced by different methods depending on the Bishop's score. Whereas labour was induced in $36.9 \%$ of controls. $75.6 \%$ cases delivered by caesarean section which was statically significant. Instrumental delivery rate was $1.5 \%$ in cases. In a study by Rizvi M and Raina R LSCS was done in $69 \%$ cases. ${ }^{16}$ High LSCS rate was because of meconium, fetal distress and previous LSCS. Meconium staining of liquor occurred in $57.8 \%$ of cases (versus $26.2 \%$ ) which was statistically significant. In a study by Brouwers $\mathrm{L}$ et al, meconium staining of liquor occurred in $47.6 \% .^{17}$

Birth weight of neonates $(3.03 \pm 0.407 \mathrm{~kg}$ versus $3.01 \pm 0$. $398 \mathrm{~kg}$ ) didn't differ. A high occurrence of NICU admissions (49.6\% versus $15.4 \%$ ), fetal distress and meconium stained liquor was seen among cases. Majority of admissions to NICU were due to meconium aspiration and prematurity. A study by Ehsan A et al, revealed NICU admission rate of $49 \%$ in obstetric cholestasis consistent with this study. ${ }^{18}$ GGT was raised in $34.8 \%$ of cases with obstetric cholestasis while bilirubin was increased in $27.4 \%$ of cases with obstetric cholestasis.

\section{CONCLUSION}

\section{From the above study it is concluded that:}

- ICP is a relatively common cause of hepatic impairment in pregnancy.

- Maternal morbidity is increased in terms of increased LSCS rates and discomfort due to pruritus. Maternal cholestasis is transient with postnatal resolution.

- ICP is associated with adverse perinatal outcome. There is increased risk of meconium staining of amniotic fluid, fetal distress, spontaneous preterm delivery and sudden IUD at term as evidenced in this study.

- Affected pregnancies require closer surveillance. A timely intervention at 37-38 weeks will reduce the adverse perinatal outcome and use of vitamin $\mathrm{K}$ injections significantly decreases the risk of postpartum haemorrhage

Funding: No funding sources Conflict of interest: None declared

Ethical approval: The study was approved by the Institutional Ethics Committee

\section{REFERENCES}

1. Geenes V, Chappell LC, Seed PT, Steer PJ, Knight M, Williamson C. Association of severe intrahepatic cholestasis of pregnancy with adverse pregnancy outcomes: a prospective population-based casecontrol study. Hepatol. 2014;59:1482-91.

2. Misra R. Ian Donalds Practical Obstetric Problem, $7^{\text {th }}$ Ed. BI Publications Pvt Ltd: New Delhi; 2014:142147.

3. Benjaminov FS, Healthcote J. Liver disease in pregnancy. Am J Gastroenterol. 2004;99:2479-88.

4. Glantz A, Marschall HU, Mattsson LA. Intrahepatic cholestasis of pregnancy: relationships between bile acid levels and fetal complication rates. Hepatol. 2004;40:467-74.

5. Rook M, Vargas J, Caughey A, Bacchetti P, Rosenthal P, Bull L. Fetal outcomes in pregnancies complicated by intrahepatic cholestasis of pregnancy in a Northern California cohort. PLoS One. 2012;7(3):e28343.

6. Royal college of obstetrics and gynecologists green top $43 \quad$ (19.5.11). Available at: https://www.rcog.org.uk/globalassets/documents/gui delines/gtg_43.pdf. Accessed on January 2014.

7. Hay JE. Liver disease in pregnancy. Hepatol. 2008;47(3):1067-76.

8. Catherine Nelson Piercy. Handbook of Obstetric Medicine $3^{\text {rd }}$ Edition, CRC Press; 2006:6:1816.

9. Milkiewiez P, Elias E, Williamson C, Weaver J. Obstetric cholestasis: may have serious 
consequences for the fetus, and needs to be taken seriously. BMJ. 2002;324:123-4.

10. Lammert F, Marschall HU, Glantz A, Matern S. Intrahepatic cholestasis of pregnancy: molecular pathogenesis, diagnosis and management. J Hepatol. 2000;33(6):1012-21.

11. Oude Elferink RP, Paulusma CC. Function and pathophysiological importance of ABCB4 (MDR3 Pglycoprotein). Pflugers Arch. 2007;453(5):601-10.

12. Kreek MJ. Female sex steroids and cholestasis. Semin Liver Dis. 1987;7(1):8-23.

13. Gonzalez MC, Reyes H, Arrese M, et al. Intrahepatic cholestasis of pregnancy in twin pregnancies. J Hepatol. 1989 Jul;9(1):84-90.

14. Reyes H, Baez M, Gonzalez MC. Selenium, zinc and copper plasma levels in IHCP, in normal pregnancies and in healthy individuals in Chile. $\mathbf{J}$ Hepatol. 2000;32(4):542-9.

15. Alsulyman OM, Ouzounian JG, Ames-castro M. IHCP; perinatal outcome associated with expectant management, Am J Obstet Gynecol. 1996;175(4 Pt 1):957-60.

16. Rizvi SM, Raina R. Fetomaternal outcome in jaundice complicating pregnancy. J Soc Obstet Gynaecol Pak. 2018;8(3):176-9.

17. Brouwers L, Koster MP, Page-Christiaens GC, Kemperman H, Boon J, Evers IM, et al. Intrahepatic cholestasis of pregnancy: maternal and fetal outcomes associated with elevated bile acid levels. Am J Obstet Gynecol. 2015;212(1):100.e1-7.

18. Ehsan A, Ehsan-ul-Haq M. Maternal and fetal outcome in patients with obstetrics cholestasis. J Soc Obstet Gynaecol Pak. 2018;8(4):227-31.

Cite this article as: Hassan N, Khurshid R, Muzamil M, Parveen S. Cholestasis of pregnancy: effects on maternal and fetal outcome. Int J Reprod Contracept Obstet Gynecol 2020;9:3202-7. 